\title{
Heat Treatment Effects on the Mechanical Properties and Morphologies of Poly (Lactic Acid)/Poly (Butylene Adipate-co-terephthalate) Blends
}

\author{
Hsien-Tang Chiu, Szu-Yuan Huang, Yan-Fu Chen, Ming-Tai Kuo, Tzong-Yiing Chiang, \\ Chi-Yung Chang, and Yu-Hsiang Wang
}

Department of Materials Science and Engineering, National Taiwan University of Science and Technology, Section 4, Keelung Road, Daan District, Taipei 106, Taiwan

Correspondence should be addressed to Hsien-Tang Chiu; hchiu@mail.ntust.edu.tw

Received 2 April 2013; Revised 15 July 2013; Accepted 30 July 2013

Academic Editor: Giridhar Madras

Copyright (C) 2013 Hsien-Tang Chiu et al. This is an open access article distributed under the Creative Commons Attribution License, which permits unrestricted use, distribution, and reproduction in any medium, provided the original work is properly cited.

In this study the relationships between mechanicals properties and morphology of the poly (lactic acid) (PLA)/poly (butylene adipate-co-terephthalate) (PBAT) blends with or without heat treatment were investigated. The differential scanning calorimetry (DSC) analysis showed that blends have a two-phase structure indicating that they are immiscible. On the other hand, the PLA/PBAT (30/70) blend achieved the best tensile and impact strength because of its sea-island morphology, except for high PBAT content. The PLA/PBAT (70/30) and PLA/PBAT (50/50) blends showed irregular and directive-layer morphologies, in scanning electron microscopy (SEM) analysis, producing a break cross-section with various fiber shapes. Both blends showed lower tensile strength and impact strength than the PLA/PBAT (30/70). After heat treatment, the PLA/PBAT blends showed high modulus of tensile and HDT because of a high degree of crystallization. The high degree of crystallization in the blends, which originated in the heat treatment, reduced their impact strength and elongation. However, the effect of high degree of crystallization on the PLA/PBAT (30/70) blend was small because of its sea-island morphology.

\section{Introduction}

The large-scale production and consumption of plastics has created several problems: diminishing oil resources, increased discharge of $\mathrm{CO}_{2}$ into the atmosphere, and environmental pollution caused by waste plastics. However, the development and acceptance of biodegradable polymers might be a solution to the waste plastics problem.

Polylactic aced (PLA) is a biodegradable thermal plastic that can be manufactured from biomass materials, such as cornstarch or beet sugar [1-3]. Although PLA has excellent biodegradability and tensile strength, its elongation ability, impact strength, shock absorbance, toughness, physical aging, and heat deflection properties are unsatisfactory for practical applications $[4,5]$. Therefore, many researchers have attempted to increase the toughness, rigidity, and biodegradability of PLA by blending it with various biodegradable soft polymers, including poly (propylene carbonate) (PCC) [3], poly (butylene succinate adipate) (PBSA) [4], poly (butylene adipate-co-terephthalate) (PBAT) [5], and poly (amide elastomer) (PAE) [6]. To improve the heat distortion temperature of PLA, it can be dispersed with nanomontmorillonite or melt-blended with high-temperature-resistant engineering plastics $[7,8]$. However, the resulting improvement in toughness remains far less than that of soft polymers.

In recent years, much attention has increased on poly (lactic acid) (PLA) with poly (butylene adipate-co-butylene terephthalate) (PBAT) blend system [9-13] due to elastomeric property of the PBAT complements brittleness of the PLA. PBAT is a fully biodegradable, flexible aliphatic-aromatic copolyester designed for film extrusion and extrusion coating. Its most attractive feature is its high elongation at break [5]. Several studies $[5,11,12]$ showed that the elongation and toughness of PLA/PBAT blends were dramatically increased 
although their thermal behavior presented a two-phase structure and was immiscible. The SEM micrographs showed that the toughening mechanism of PLA/PBAT blends was from brittle fracture of the PLA to ductile fracture of the blends. Therefore, the immiscible polymer blends and their morphologies have important effects on mechanical properties. The studies above focused on low PBAT contents. Li et al. [13] have investigated the PLA/PBAT blends with high PBAT contents, but they devoted their study to relationships between rheological properties and morphology of the blends.

On the other hand, the heat deflection of the resulting PLA-based materials requires further improvement for practical applications. Compared to the general crystalline polymer polypropylene (PP), PLA has a similar Tm value but a much higher glass transition temperature $\left(T_{g}\right)$. However, PLA has a much lower heat deflection than PP. The main reason for this phenomenon is that although PLA is a crystalline polymer, almost no crystallization occurs during the molding process in practice, as evidenced from its thermal behavior during differential scanning calorimetry (DSC) $[5,10]$.

As mentioned, few studies have investigated the improvement of PLA-based HDT and the relationships between mechanicals properties and morphology for the PLA/PBAT blends. Therefore, the objectives of the present work are to blend PLA with PBAT using a melt-blending method in a twin-screw extruder. The various PLA/PBAT blends were prepared by injection molding. The PLA/PBAT blends were annealed at $100^{\circ} \mathrm{C}$ for $8 \mathrm{~h}$ and $24 \mathrm{~h}$ investigate the effects of crystallization on their tensile strength, impact strength, and heat deflection. We tested the tensile strength, Izod impact strength, DSC, SEM, XRD, and HDT to investigate the relationships between the morphology and mechanical properties of the PLA/PBAT blends. This study also presents a discussion of the effects of various heat treatment conditions on mechanical properties.

\section{Experimental}

2.1. Materials and Samples Preparation. The PLA (polymer 2100D) and PBAT (ECOFLEX 7011) polymers used in this study were obtained from NatureWorks and BASF, respectively. The PLA and PBAT pellets were dried in a vacuum oven at $80^{\circ} \mathrm{C}$ for $8 \mathrm{~h}$ prior to use and subsequently meltblended in a twin-screw extruder operating at a mixing speed of $600 \mathrm{rpm}$ at $150-160^{\circ} \mathrm{C}$. The PLA/PBAT weight ratios were 100/0, 70/30, 50/50, 30/70, and 0/100. After blending, all of the samples were cooled to room temperature in an air atmosphere. Samples of the blends were molded at $180^{\circ} \mathrm{C}$ using an injection-molding instrument (SPC-303BL Type, Yeun Chenn), with process times of approximately $100 \mathrm{~s}$ (injection), $20 \mathrm{~s}$ (forming), and $260 \mathrm{~s}$ (cooling). The processes were performed at a mold temperature of $40^{\circ} \mathrm{C}$.

\subsection{Measurements}

2.2.1. DSC. The DSC analysis in this study was conducted using a Perkin-Elmer DSC-PYRIS-1 instrument equipped with an ice-water and liquid nitrogen cooler. Indium was used to calibrate the temperature and the heat of fusion. The amount of sample used for the measurements was approximately $4-7 \mathrm{mg}$. The initial scan of the specimens proceeded from 40 to $200^{\circ} \mathrm{C}$ at a rate of $10^{\circ} \mathrm{C} / \mathrm{min}$ under a $\mathrm{N}_{2}$ atmosphere. The melt-quenched scans of the specimens were similar to their initial scans. The specimens were heated to $200^{\circ} \mathrm{C}$ and held at that temperature for $1 \mathrm{~min}$ to erase their thermal history. They were then cooled to $40^{\circ} \mathrm{C}$ at a rate of $100^{\circ} \mathrm{C} / \mathrm{min}$. The thermograms of the specimens were subsequently obtained by heating at a rate of $10^{\circ} \mathrm{C} / \mathrm{min}$ from 40 to $200^{\circ} \mathrm{C}$. All of the samples were annealed in an oven at $100^{\circ} \mathrm{C}$ for 8 and $24 \mathrm{~h}$ after injection molding. The thermograms of the samples from 40 to $200^{\circ} \mathrm{C}$ were then obtained at a heating rate of $10^{\circ} \mathrm{C} / \mathrm{min}$.

2.2.2. Wide-Angle X-Ray Diffraction (WAXD). Samples were analyzed using a Shimadzu XRD-6000 WAXD apparatus and $\mathrm{Cu} \mathrm{K} \alpha$ radiation $(\lambda=0.154 \mathrm{~nm})$ under a voltage of $40 \mathrm{kV}$ and a current of $100 \mathrm{~mA}$. Diffraction intensities were counted in $0.05^{\circ}$ steps at a scanning speed of $5^{\circ} / \mathrm{min}$. The spectra were recorded in an angular $2 \theta$ range from 10 to $40^{\circ}$ at room temperature.

2.2.3. Tensile Strength. The tensile strengths of the blends were evaluated using a tensile-testing machine (MTS Qtest5) and material-testing software (Test Work 4). The tensile strength tests were performed at $25^{\circ} \mathrm{C}$ with a cross-head speed of $100 \mathrm{~mm} / \mathrm{min}$ and a $5 \mathrm{kN}$ load cell.

2.2.4. Impact Test. Impact tests were performed at room temperature using an Izod Impact testing machine with a pendulum weight of $1.377 \mathrm{kgf}$, a pendulum angle of $150^{\circ}$, and a distance from the pendulum head of $32.83 \mathrm{~cm}$.

2.2.5. Heat Deflection Temperature (HDT). The HDT tests in this study were performed using a GOTECH HV-2000 A HDT testing machine operating at a heating rate of $2^{\circ} \mathrm{C} / \mathrm{min}$ and a load of 66 psi.

\section{Results and Discussion}

3.1. Phase Transition Regions and Miscibility. Semicrystalline polymers possess amorphous and crystalline phases, each of which has at least a phase transition region, that is, a glass transition temperature $\left(T_{g}\right)$ and a melting temperature $\left(T_{m}\right)$. The phase transition regions can be determined by DSC analysis, revealing the miscibility of polymer blends. A miscible polymer blend is homogeneous and usually displays a single $T_{g}$ between those of the pure components, whereas a compatible blend shows both $T_{g} s$ although these eventually shift toward one another.

The thermograms of all samples in the initial and meltquenched scans have several endothermic regions (Figures 1 and 2). Table 1 lists the characteristic temperatures of glass transition regions for all samples. The glass transition temperatures $\left(T_{g}\right)$ in this study were determined by the halfheat capacity $\left(1 / 2 C_{p}\right)$ in the glass transition region. The PLA in the initial and melt-quenched DSC thermograms showed 
TABLE 1: Characteristic temperatures of phase transition and enthalpy values of PLA/PBAT blends in the initial scan of DSC.

\begin{tabular}{|c|c|c|c|c|c|c|}
\hline Code & $T_{g \text {-PBAT }}{ }^{1}$ & $T_{g \text {-PLA }}{ }^{2}$ & $\Delta T_{g}^{3}$ & $\Delta H_{\mathrm{cc}}^{4}(\mathrm{~J} / \mathrm{g})$ & $T_{m-\mathrm{PLA}}{ }^{5}\left({ }^{\circ} \mathrm{C}\right)$ & $\Delta H_{m-\mathrm{PLA}}{ }^{5}(\mathrm{~J} / \mathrm{g})$ \\
\hline PLA & - & 60.7 & - & -17.39 & 164.1 & 37 \\
\hline PLA/PBAT $(70 / 30)$ & -32.1 & 59.7 & 91.8 & -13.71 & 164.3 & 22.38 \\
\hline PLA/PBAT (50/50) & -32.8 & 59.2 & 91.0 & -7.39 & 163.9 & 16.58 \\
\hline PLA/PBAT $(30 / 70)$ & -30.9 & 57.6 & 88.5 & -3.61 & 163.7 & 9.91 \\
\hline PBAT & -34 & - & - & & & \\
\hline
\end{tabular}

${ }^{1} T_{g \text {-PBAT }}$ The temperature of glass transition region of PBAT.

${ }^{2} T_{g \text {-PLA }}$ : The temperature of glass transition region of PLA.

${ }^{3} \Delta T_{g}: \Delta T_{g}=T_{g-\text { PLA }}-T_{g-\text { PBAT }}$.

${ }^{4} \Delta H_{\mathrm{cc}}$ : The exothermal enthalpy of PLA cold-crystallization (re-crystallization).

${ }^{5} T_{m \text {-PLA }}$ and $\Delta H_{m \text {-PLA }}$ : The melting temperature and crystal melting enthalpy of PLA.

TABLE 2: Characteristic temperatures of phase transition and enthalpy values of PLA/PBAT blends in the melt-quenched scan of DSC.

\begin{tabular}{|c|c|c|c|c|c|c|}
\hline Code & $T_{g \text {-PBAT }}{ }^{1}$ & $T_{g \text {-PLA }}{ }^{2}$ & $\Delta T_{g}{ }^{3}$ & $\Delta H_{\mathrm{cc}}^{4}(\mathrm{~J} / \mathrm{g})$ & $T_{m-\mathrm{PLA}}{ }^{5}\left({ }^{\circ} \mathrm{C}\right)$ & $\Delta H_{m-\mathrm{PLA}}{ }^{5}(\mathrm{~J} / \mathrm{g})$ \\
\hline PLA & - & 59.2 & - & -21.31 & 164.3 & 37.2 \\
\hline PLA/PBAT $(70 / 30)$ & -33.6 & 60.1 & 93.4 & -17.59 & 164.9 & 22.29 \\
\hline PLA/PBAT (50/50) & -32.9 & 59.5 & 92.4 & -10.41 & 165.3 & 14.36 \\
\hline PLA/PBAT $(30 / 70)$ & -30.1 & 57.2 & 87.3 & -6.84 & 165.2 & 9.65 \\
\hline PBAT & -35.1 & - & - & - & - & - \\
\hline
\end{tabular}

${ }^{1} T_{g \text {-PBAT }}$ The temperature of glass transition region of PBAT.

${ }^{2} T_{g \text {-PLA }}$ : The temperature of glass transition region of PLA.

${ }^{3} \Delta T_{g}: \Delta T_{g}=T_{g-\text { PLA }}-T_{g-\text { PBAT }}$.

${ }^{4} \Delta H_{\mathrm{cc}}$ : The exothermal enthalpy of PLA cold-crystallization (re-crystallization).

${ }^{5} T_{m \text {-PLA }}$ and $\Delta H_{m \text {-PLA }}$ : The melting temperature and crystal melting enthalpy of PLA.

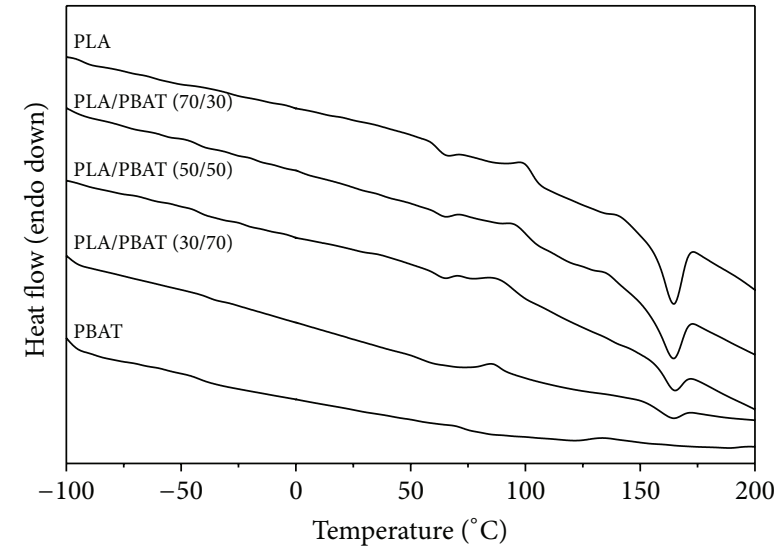

FIGURE 1: Initial scanning DSC thermogram of PLA/PBAT blends.

a $T_{g}$ and $T_{m}$ of $60^{\circ} \mathrm{C}$ and $165^{\circ} \mathrm{C}$, respectively, whereas the PBAT displayed $T_{g}$ and $T_{m}$ of approximately $-33^{\circ} \mathrm{C}$ and $112^{\circ} \mathrm{C}$, respectively (Tables 2 and 3 ). This result shows that PLA and PBAT are biodegradable crystalline plastics with amorphous and crystalline phases. The PBAT has a lower $T_{g}$ broader $T_{m}$ region than PLA (Figures 1 and 2 ) and provides good softness and impact resistance.

3.1.1. Glass Transition Region of Blends. The PLA/PBAT blends in the initial and melt-quenched scan exhibit 2 glass transition regions at approximately -35 to $-30^{\circ} \mathrm{C}$ and 57 to

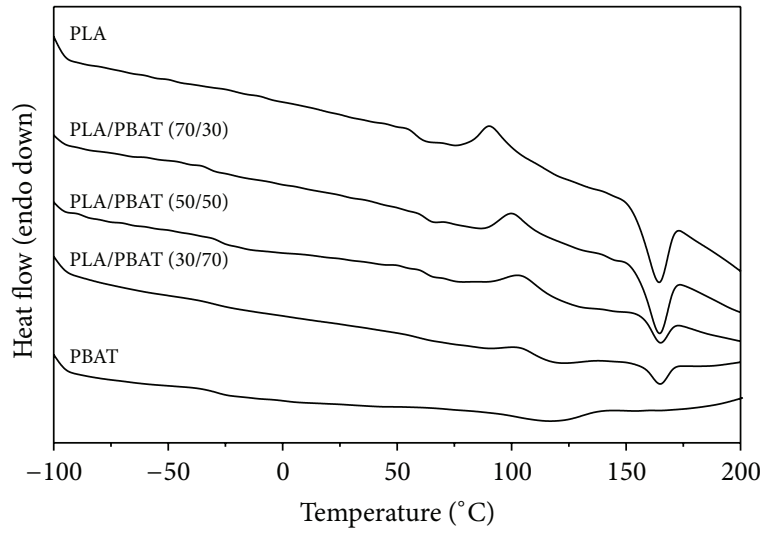

FIGURE 2: Melt-quenched scanning DSC thermogram of PLA/PBAT blends.

$61^{\circ} \mathrm{C}$. These regions are, respectively, associated with PBAT and PLA $T_{g}\left(T_{g \text {-PBAT }}\right.$ and $\left.T_{g \text {-PLA }}\right)$ regions (Figures 1 and 2 ). The PLA/PBAT blends exhibit two $T_{g}$ regions, indicating that the blends are immiscible and present a two-phase structure. However, the $T_{g \text {-PBAT }}$ and $T_{g \text {-PLA }}$ values for various PLA/PBAT blends in the initial and melt-quenched scans changed in a small region at approximately -30 to $-35^{\circ} \mathrm{C}$ and 57 to $61^{\circ} \mathrm{C}$, respectively (Tables 1 and 2). Accordingly, the PLA and PBAT in the PLA/PBAT blends present a low compatibility. The $\Delta T_{g}\left(T_{g \text {-PLA }}-T_{g \text {-PBAT }}\right)$ represents the degree of compatibility, which is affected by its morphology. 
TABLE 3: The enthalpy and crystallinity of PLA/PBAT blends treated at $100^{\circ} \mathrm{C}$ for 8 and $24 \mathrm{hr}$.

\begin{tabular}{|c|c|c|c|c|c|c|}
\hline \multirow{2}{*}{ Code } & \multicolumn{2}{|c|}{$0 \mathrm{hr}$} & \multicolumn{2}{|c|}{$8 \mathrm{hr}$} & \multicolumn{2}{|c|}{$24 \mathrm{hr}$} \\
\hline & $\Delta H_{m}{ }^{\mathrm{a}}(\mathrm{J} / \mathrm{g})$ & $X_{c}^{\mathrm{b}}(\%)$ & $\Delta H_{m}{ }^{a}(\mathrm{~J} / \mathrm{g})$ & $X_{c}^{\mathrm{b}}(\%)$ & $\Delta H_{m}{ }^{a}(\mathrm{~J} / \mathrm{g})$ & $X_{c}^{\mathrm{b}}(\%)$ \\
\hline PLA & 37 & 42.44 & 39.47 & 43.44 & 31.59 & 34 \\
\hline PLA/PBAT (70/30) & 22.38 & 32.3 & 24.03 & 33.3 & 21.23 & 32.61 \\
\hline PLA/PBAT (50/50) & 16.58 & 33.72 & 16.32 & 35.1 & 15.68 & 33.72 \\
\hline PLA/PBAT (30/70) & 9.91 & 34.62 & 9.66 & 34.62 & 9.14 & 32.76 \\
\hline
\end{tabular}

${ }^{\mathrm{a}} \Delta H_{m}:$ The crystal melting enthalpy of PLA.

${ }^{\mathrm{b}} X_{c}$ : The degree of crystallinity $\left(X_{c}\right)$ of PLA.

The PLA/PBAT (30/70) has the lowest $\Delta T_{g}$ value, and the $\Delta T_{q}$ values for both PLA/PBAT (70/30) and PLA/PBAT (50/50) are relatively similar (Tables 1 and 2 ). This result indicates that the blends have at least two morphologies. The following SEM analysis presents the phase-separation structure and morphologies of these samples.

The PLA/PBAT blends that underwent the meltquenched process determine the compatibility of the blends and their phase-separation behavior. The $T_{g}$ values $\left(T_{g \text {-PBAT }}\right.$ and $\left.T_{g \text {-PLA }}\right)$ under the melt-quenched scan for PLA and PBAT appeared to decrease slightly, and their $T_{g}$ regions were broader than the initial scan (Table 1 and Figures 1 and 2 ). This result indicates that the amorphousness of PBAT and PLA increased under the melt-quenched process. The $T_{g}$ regions in PLA/PBAT blends after the melt-quenched scan also show two $T_{g}$ regions associated with the PBAT and PLA $T_{g}$ regions, respectively. The $\Delta T_{g}, T_{g \text {-PBAT }}$, and $T_{g \text {-PLA }}$ values for PLA/PBAT blends after the melt-quenched process have exhibited a slight variation within the region of $2^{\circ} \mathrm{C}$ (Tables 1 and 2). Therefore, the morphologies of the blends are two-phase structures, and the compatibility of blends is low because the $T_{g}$ values have no obvious variation after the melt quenching process. Spinodal decomposition (SD) is a mechanism for the rapid unmixing of a mixture of liquids or solids from one thermodynamic phase to form two coexisting phases during rapid cooling process [14]. The twophase separation of PLA/PBAT blends is due to SD during proceeding in the quenching process [15]. The morphology of PLA/PBAT (30/70) structure after the quenching process was presented by a polarized optical microscope (POM) (Figure 11). It can be seen that PLA/PBAT blends exhibited the irregularly interwoven phase. As reported previously, SD typically yields an interwoven structure [16]. Thus, it might be implied that the morphology of PLA/PBAT was attributed to SD in the quenching process. The thermograms of $T_{g}$ region for PLA at approximately $63^{\circ} \mathrm{C}$ show a melt-like peak, which disappears under melt-quenched scanning (Figures 1 and 2). This result suggests an enthalpy relaxation resulting from physical aging of PLA amorphous macromolecular chains [17]. This aging process involves certain local density changes of the amorphous phase, generating nuclei and facilitating the crystallization of PLA [18].

3.1.2. Melting Transition Region. The crystal-melting temperature of PLA $\left(T_{m \text {-PLA }}\right)$ in the initial scan presented melting at approximately $164^{\circ} \mathrm{C}$, but the PBAT had no obvious melting endothermic region (Figure 1). The PLA/PBAT blends in the initial scanning displayed a crystal-melting endothermic region at approximately $164^{\circ} \mathrm{C}$, and the enthalpy values in the initial scanning for the PLA/PBAT blends increased almost linearly as the PLA content increased (Table 2). Accordingly, the melting endothermic region of PLA/PBAT blends is associated with PLA crystallization. The melting-temperature $\left(T_{m \text {-PLA }}\right)$ regions of the PLA and PLA/PBAT blends after melt-quenched scanning remained at approximately $164^{\circ} \mathrm{C}$, and their crystal-melting enthalpy $\left(\Delta H_{m}\right)$ values showed no obvious change (Tables 1 and 2). The uniform $\Delta H_{m}$ values before and after melted-quenched scanning (Tables 1 and 2) indicate that the PLA in the PLA/PBAT blends has a high rate of crystallization or high crystallization ability. These results illustrate a high degree of phase separation for the PLA/PBAT because the crystallization ability does not change significantly under the melt quenching process. Therefore, the PLA and PBAT in the blends tend to form independent phases. The PLA and PLA/PBAT blends in the DSC curves at approximately $80-100^{\circ} \mathrm{C}$ under the initial and melt-quenched scans exhibit that an exothermal peak is associated with PLA recrystallization (cold crystallization). This is because the PLA in all samples has the only crystallization ability. This PLA recrystallization likely results from the cold crystallization processes of PLA because the cold crystallization only presents a polymer with a high crystallization ability. The region of the cold crystallization temperature and the enthalpies $\left(\Delta H_{\mathrm{cc}}\right)$ of crystal exothermal peak were almost uniform under the initial and melt-quenched scanning (Tables 1 and 2), indicating that the PBAT composition in the blends hardly affects the crystallization ability of PLA. Thus, the PLA and PBAT in the PLA/PBAT blends tend to form independent phase. Accordingly, the PLA/PBAT blends should exhibit a two-phase structure, as further verified in SEM analysis.

To further investigate the crystalline characteristics of PLA/PBAT blends, all samples were annealed at $100^{\circ} \mathrm{C}$ for 8 and $24 \mathrm{~h}$ and were analyzed using DSC and WAXD. Figure 3 shows that the melting temperatures of PLA/PBAT blends remained at approximately $164^{\circ} \mathrm{C}$, indicating that their crystalline form remained unchanged by the annealing process. However, the enthalpy of melting crystal $\left(\Delta H_{m}\right)$ and degree of crystallization $\left(X_{c}\right)$ for the PLA/PBAT blends increased after annealing (Table 4 ). The $\Delta H_{m}$ and $X_{c}$ reached their maximum values after annealing at $100^{\circ} \mathrm{C}$ for $8 \mathrm{~h}$ and underwent thermal aging when annealed for longer times (24h) as observed from the drop in crystallinity values. This increase in the $\Delta H_{m}$ and $X_{c}$ values might result from 
TABLE 4: The impact strength $(\mathrm{KJ} / \mathrm{m})$ for all samples under the melt-quenching and various annealing.

\begin{tabular}{lcccc}
\hline & Melt-quenching & Annealing at $100^{\circ} \mathrm{C}$ for $24 \mathrm{~h}$ & ${\text { Annealing at } 100^{\circ} \mathrm{C} \text { for } 8 \mathrm{~h}}^{\text {Break after Izod impact Testing }^{1}}$ \\
\hline PLA & 3.85 & 3.85 & 3.62 & $\circ$ \\
PLA/PBAT (70/30) & 19.03 & 13.65 & 12.11 & 0 \\
PLA/PBAT (50/50) & 18.77 & 7.57 & 7.01 & $\circ$ \\
PLA/PBAT (30/70) & 33.56 & 21.6 & 22.58 & $\times$ \\
PBAT & 30.5 & 30.75 & 29.24 & $\times$ \\
\hline
\end{tabular}

०: Fracture.

$\times$ : Has not destroy.

${ }^{1}$ The extent of damage of sample after Izod impact testing.

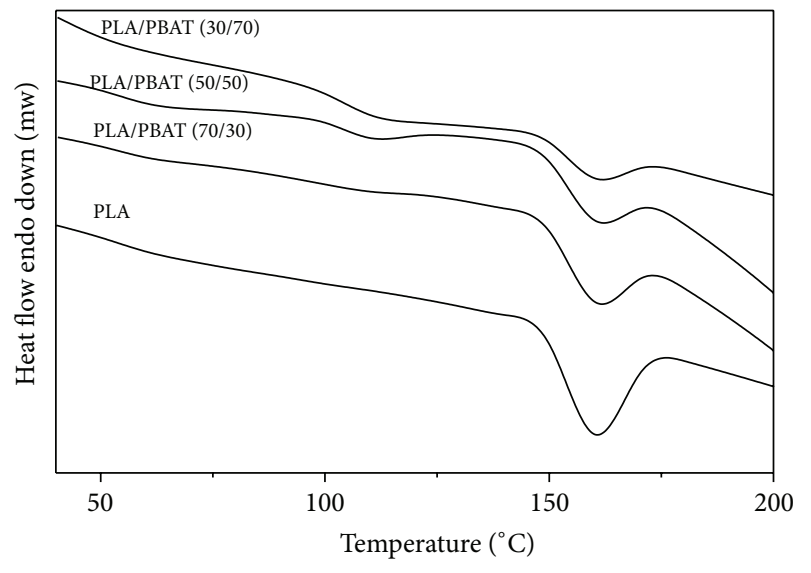

Figure 3: PLA/PBAT blends DSC annealing at $100^{\circ} \mathrm{C}$ for $8 \mathrm{hr}$.

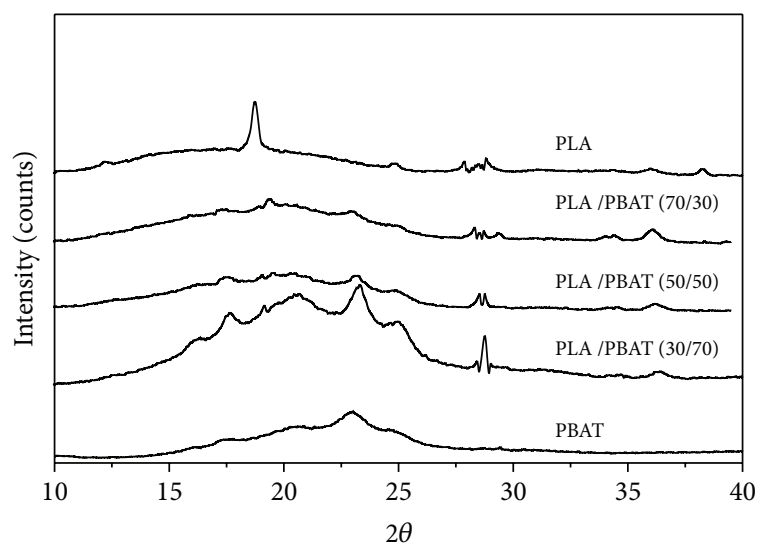

FIGURE 4: WAXD patterns of the untreated P LA/PBAT blends.

the high-oriented amorphous PLA macromolecular chains, which can easily incorporate the PLA crystalline lattice. Therefore, the PLA macromolecular chains with a high orientation recrystallize (cool-crystallize) at $80-100^{\circ} \mathrm{C}$ (Figures 1 and 3). The cool-crystalline structure disappeared after the annealing process (Figure 3 ), but $H_{m}$ and $X_{c}$ increased (Tables 1 and 2). These results verify that the macromolecular chains of high orientation merged with the raw crystals during the annealing process.

We also investigated the characteristics of the crystals and effects of annealing on the PBAT/PLA blends using WAXD (Figures 4 and 5). Figure 4 shows that the WAXD curves

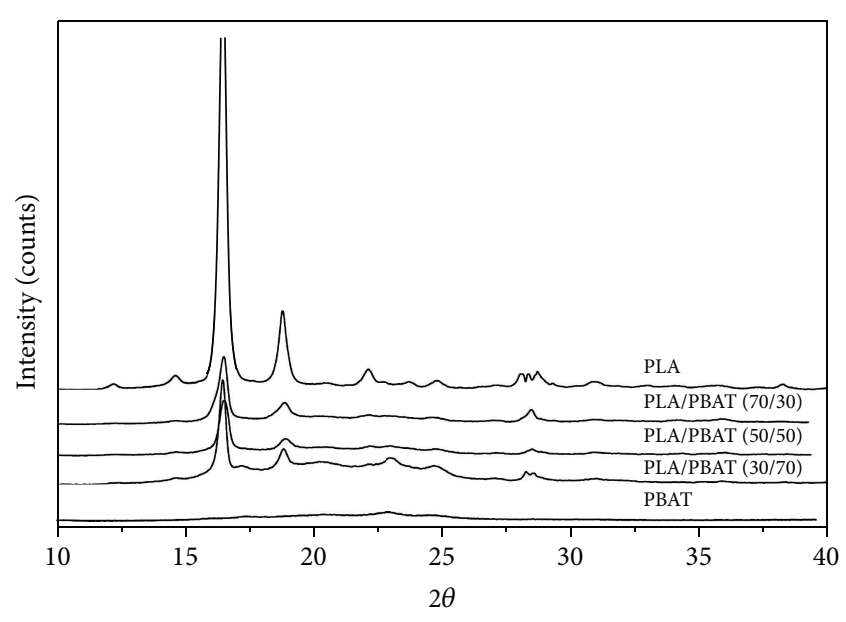

FIgURE 5: WAXD patterns of PLA/PBAT blends annealing at $100^{\circ} \mathrm{C}$ for $8 \mathrm{hrs}$.

for the untreated PLA present a strong diffraction peaks at $2 \theta=18.7^{\circ}$ corresponding to the (203) crystal plane [10]. The WAXD peaks for the untreated PLA/PBAT blends were almost the same as those for PLA, but the diffractive intensities of blends are lower than those of the PLA because of a low PLA content. Several small diffraction peaks appeared in all samples and might be associated with PLA microcrystallinity (Figure 4). The WAXD peaks of PLA and PLA/PBAT blends annealed for $8 \mathrm{~h}$ at $100^{\circ} \mathrm{C}$ exhibited strong diffraction peaks at $2 \theta=17.5^{\circ}$, except for $2 \theta=18.7^{\circ}$ (Figure 5). The maximum value of diffractive intensity for the PLA/PBAT blends in all diffraction peaks appears at $2 \theta=17.5^{\circ}$ corresponding to the (200/110) crystal plane [10]. This result indicates that the PLA composition in the PLA/PBAT blends under the annealing process exhibits an orientation crystalline structure that originates in the amorphous PLA macromolecular chains of high orientation. The orientation of macromolecular chains in the study is caused by the shearing force under the mixed and injection-molding process. Accordingly, the $\Delta H_{m}$ and $X_{c}$ values of the PLA/PBAT blends annealed for $8 \mathrm{~h}$ and $24 \mathrm{~h}$ are higher than those for untreated samples (Table 3 ). The $\Delta H_{m}$ and $X_{c}$ values of the PLA and PLA/PBAT blends annealed at $100^{\circ} \mathrm{C}$ for $24 \mathrm{~h}$ are slightly lower than those of samples annealed for $8 \mathrm{~h}$ (Table 3), verifying that the PLA crystal undergoes thermal aging when annealed at $100^{\circ} \mathrm{C}$ for $24 \mathrm{~h}$. The amorphous PLA macromolecular chains of high orientation verify the effects of cool crystallization on 


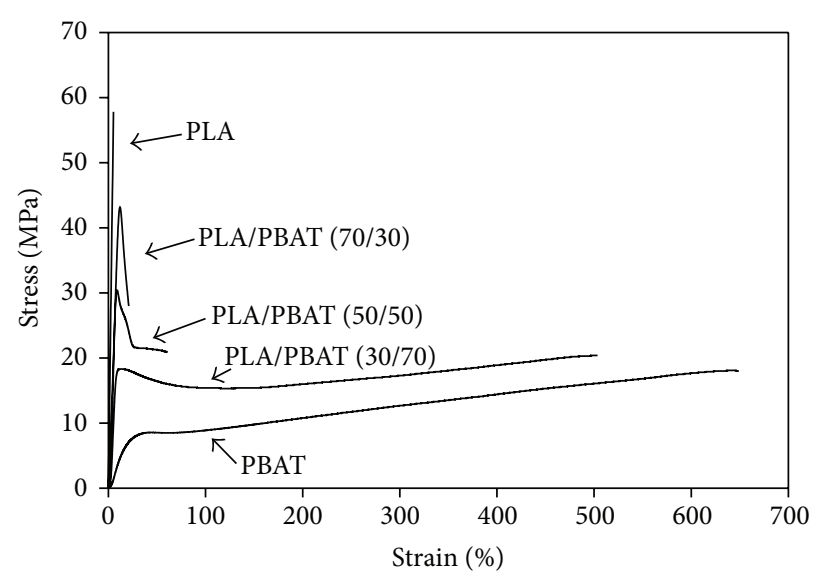

(a)

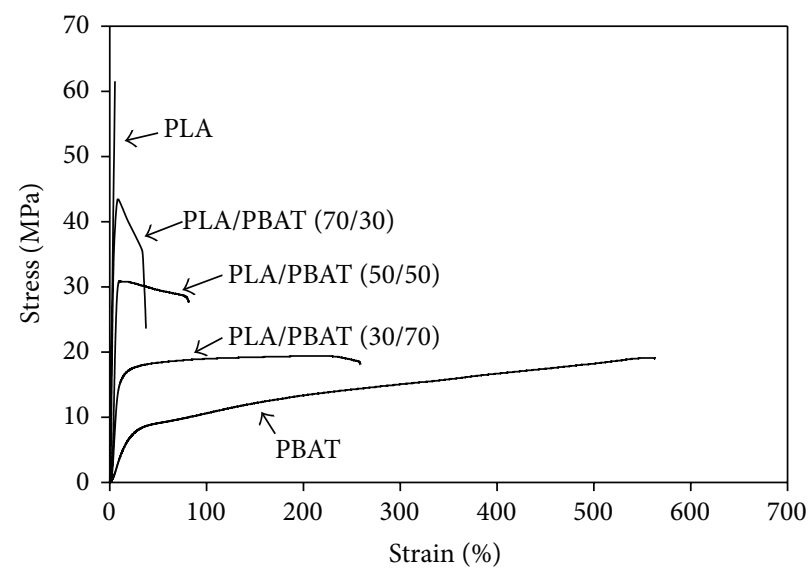

(b)

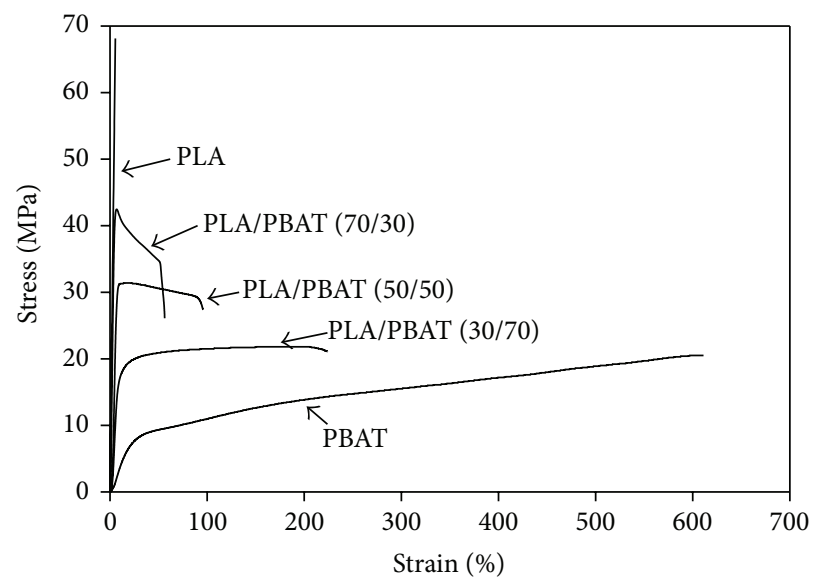

(c)

Figure 6: The tensile stress-strain curves of PLA/PBAT blends recorded at room temperature $\left(27^{\circ} \mathrm{C}\right)$. (a) Untreated, (b) Annealed at $100^{\circ} \mathrm{C}$ for $8 \mathrm{hrs}$, (c) annealed at $100^{\circ} \mathrm{C}$ for $24 \mathrm{hrs}$.

the initial and melt-quenched DSC scanning. We use the PLA that is an extrusion grade plastic with a low crystallinity. Thus, although the DSC heating thermograms of the PLA did not show melting endothermal peak, its DSC cooling thermograms displayed a broad weak melting exothermal peak in the temperature range of $105-45^{\circ} \mathrm{C}$ (Figure 1(b)).

3.2. Mechanical Properties and Morphologies. As mentioned in the DSC and WAXD analyses, the PLA in the blends was a semicrystalline polymer with a high crystallization ability. Conversely, the PBAT presented features of an amorphous polymer. The PLA/PBAT blends had two-phase structure. The compatibility and morphology of the blends, which are associated with their components, determine the mechanical properties such as tensile and impact strength. This section presents the relationships between mechanical properties and morphologies as revealed by tensile strength and impact strength tests.

3.2.1. Tensile Strength. Figure 6(a) shows the stress-strain curves of all untreated samples at room temperature. PLA has a high stress and high initial modulus, but its strain is low, indicating that the PLA is a hard plastic. The PBTA tensile property is contrary to PLA; it possesses a high strain above $600 \%$ and a low modulus at approximately $15 \mathrm{Mpa}$, which is similar to thermal plastic elastomers. The stress-strain curves for PLA/PBAT blends show that the strain values at break increased with the PBAT content, but the stress values at break presented a reverse tendency, (Figure 6(a)). The PLA/PBAT (30/70), PLA/PBAT (50/50) and PLA/PBAT (70/30) exhibited a yield point; subsequently, they exhibited plastic elongation. These results indicate that the blends present greater softness than the PLA. Accordingly, the PBTA in the PLA/PBAT blends toughens the blends. The cross-section of SEM patterns shows relationships among the behavior of break, tensile properties, and morphologies of the samples. These samples underwent a quenched break under liquid nitrogen (Figures 7(a)-7(e)). The PLA under the quenched break showed a brittle and low-deformed break, and break tracks presented a considerable acute angle (Figure 7(a)). The PBAT also exhibited a brittle break, but its break angle was alleviative, and its break tracks were longer than PLA (Figure 7(b)). The break cross-sections of 


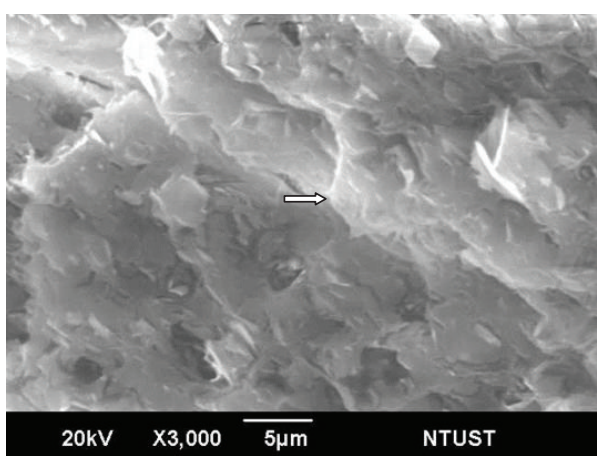

(a) PLA

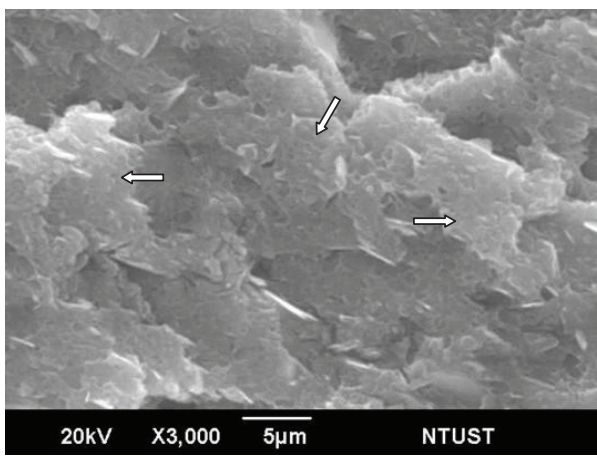

(c) PLA/PBAT (70/30)

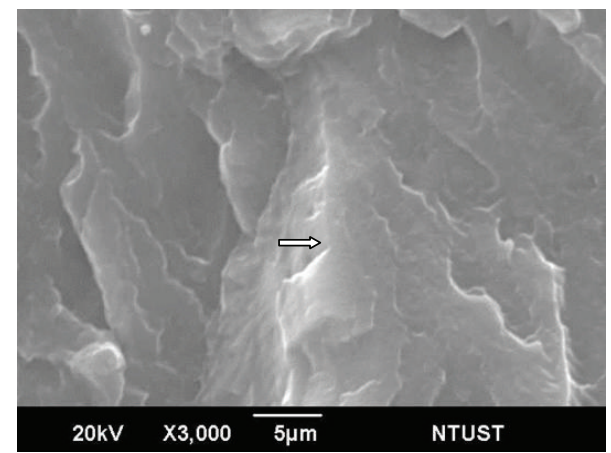

(b) PBAT

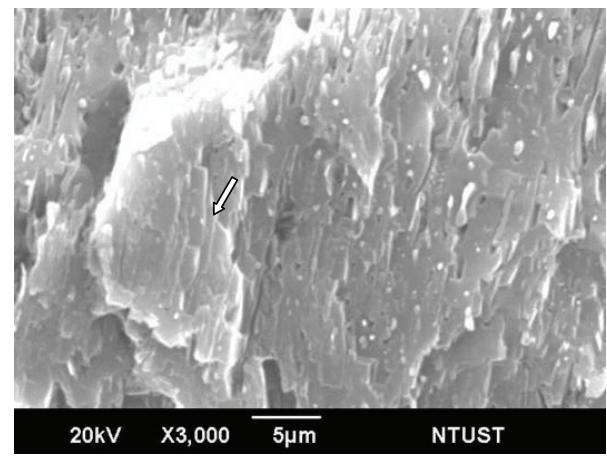

(d) PLA/PBAT (50/50)

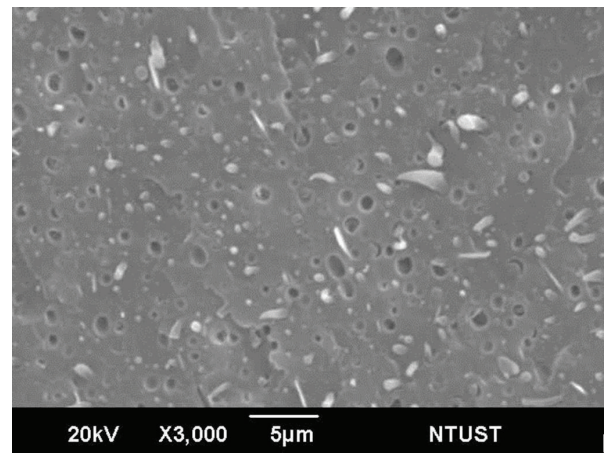

(e) PLA/PBAT (30/70)

FIGURE 7: SEM graphs of break cross-section under the quenched break of liquid nitrogen. The white arrows in (a-d) point to the break tracks.

PLA/PBAT (70/30) and PLA/PBAT (50/50) were similar to that of PLA. The PLA/PBAT (70/30) presented an irregularlayer break cross-section and the PLA/PBAT (50/50) a directive-layer break cross-section (Figures $7(\mathrm{c})$ and $7(\mathrm{~d})$ ). The PLA/PBAT (30/70) showed that PLA was spheroid dispersed on a PBAT continuous phase, which is similar to the morphology of reinforcement for rubber toughness (Figure 7(e)). The PLA/PBAT (70/30) and PLA/PBAT (50/50) have lower elongation plastic deformation than the PLA/PBAT (30/70), as shown in the stress-strain curves in Figure 6(a). The PLA/PBAT (30/70) in all blends had the highest elongation (above $500 \%$ ). The morphologies of blends on the effect of tensile strength are apparently revealed on the break cross-section of tensile testing at room temperature; the PLA and PBAT break cross-section, respectively, present an acute-angle section with fibrillose (Figure 8(a)) and slightly concave-convex plane morphologies (Figure 8(b)). The break cross-section for PLA/PBAT (70/30) and PLA/PBAT (50/50) presented numerous directive fiber shapes (Figures $8(\mathrm{c})$ and $8(d))$. The bunch of directive fiber shapes under tensile testing at room temperature originates in the irregular and directive PLA-layer phase because the PLA layer phases undergo directional tensile force. The PLA layer phases are subsequently extracted from the PLA/PBAT mixed phase and broken (Figures $8(\mathrm{a})-8(\mathrm{e})$ ). The break of acute angle and the bunch of fiber shape at the tensile break only appears in the PLA, PLA/PBAT (50/50), and PLA/PBAT (70/30) samples. However, the PLA/PBAT (30/70) exhibits an irregular concave break cross-section (Figure $8(\mathrm{e})$ ), which has concave sizes within $100 \mathrm{um}$. The PLA/PBAT (30/70) presents an 


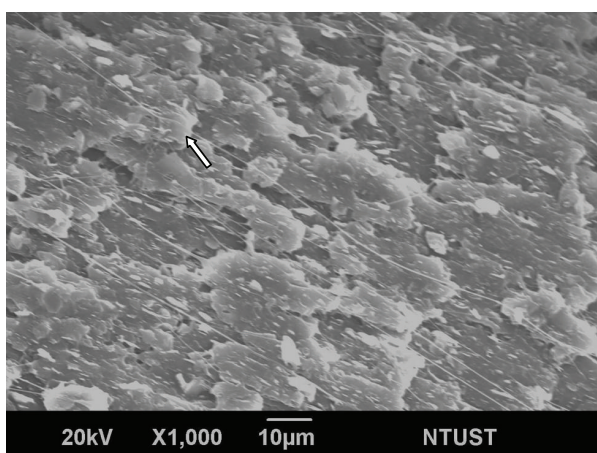

(a) PLA

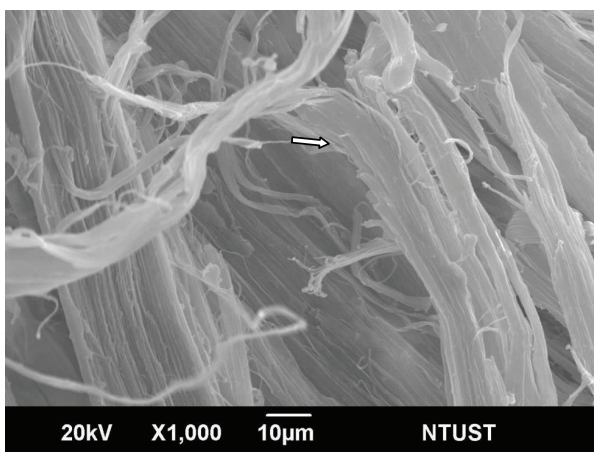

(c) PLA/PBAT (50/50)

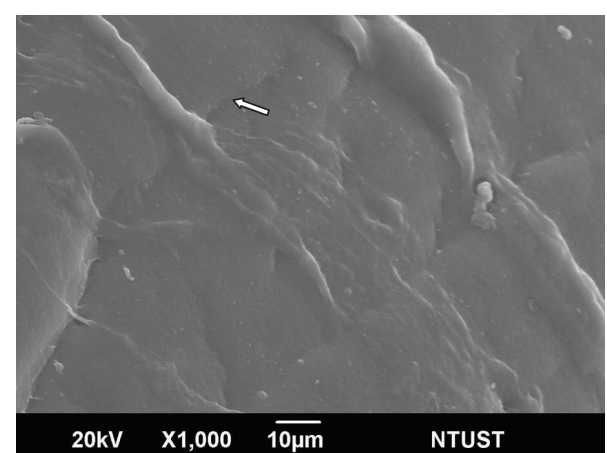

(b) PBAT

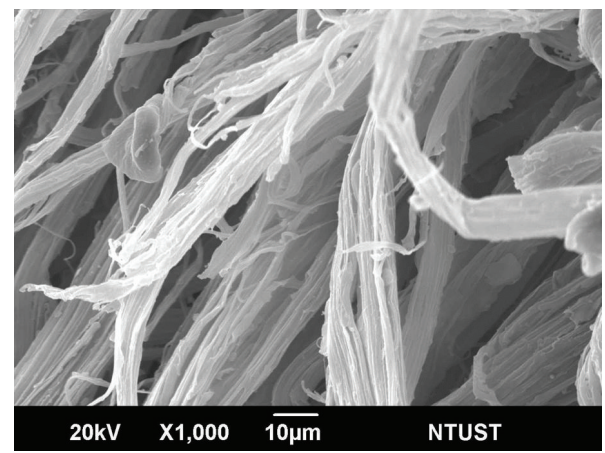

(d) PLA/PBAT (70/30)

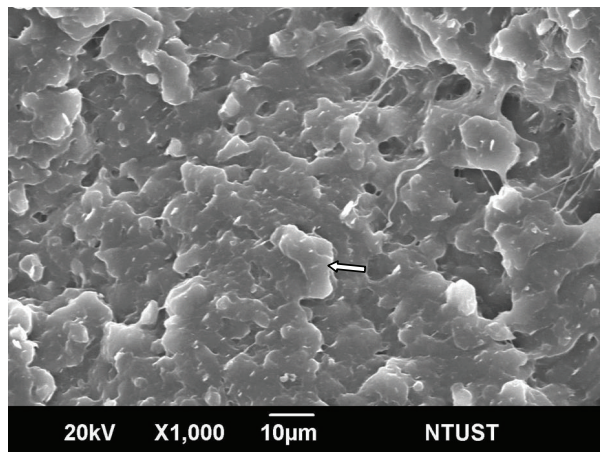

(e) PLA/PBAT (30/70)

FIGURE 8: SEM graphs of break cross-section break on tensile testing at room temperature. The white arrows in (a-e) point to the break tracks.

PLA irregular disperse phase that is dispersed in a PBAT continuous phase; that is, it has a sea-island morphology consisting of the PLA irregular island-phase and the PBTA sea-phase (Figure 8(e)). Because the PLA-dispersed phase is distributed over the PBAT continuous phase, which agrees with a toughened structure, the PLA/PBAT (30/70) has a higher elongation. Therefore, the PLA/PBAT (30/70) has a higher impact strength, as discussed in the following section.

3.2.2. Impact Strength. The components and morphologies of PLA/PBAT blends affect their impact strengths. Table 4 shows the characteristics of impact at room temperature as determined by Izod Impact testing. The PLA, PLA/PBAT (70/30), and PLA/PBAT (50/50) exhibited an impact fracture, whereas PBAT and PLA/PBAT (30/70) had impact strength values $(\mathrm{Kgf} / \mathrm{cm})$ lower than those of PLA/PBAT (30/70) and
PBAT. The impact strength of PLA/PBAT blends increased with the PBAT content. The impact strength of PLA/PBAT (30/70) was slightly higher than that of PBAT. This result indicates that the morphologies of the PLA/PBAT blends have a significant effect on the impact strength, except for the PBAT content of the blend. As mentioned, the PLA/PBAT $(30 / 70)$ exhibits an irregular sea-island morphology that has the effect of rubber toughening. Therefore, the PLA/PBAT (30/70) possesses a high impact strength. The impact strength of PLA/PBAT (50/50) is lower than that of PLA/PBAT (30/70), because PLA/PBAT (50/50) has a directive layer morphology (Figure 7(d)), and PLA/PBAT (70/30) has an irregular-layer morphology, even if PLA/PBAT (50/50) has a higher PBAT content than the PLA/PBAT (70/30). The morphologies of PLA/PBAT (50/50) and PLA/PBAT (70/30) after impact testing at room temperature are an acute angle 


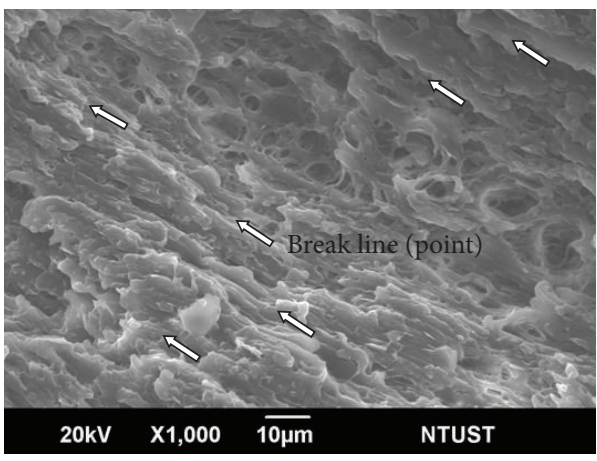

(a) PLA/PBAT (50/50)

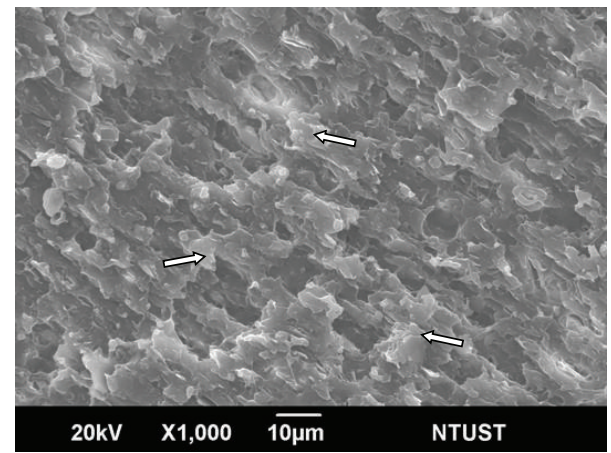

(b) PLA/PBAT (70/30)

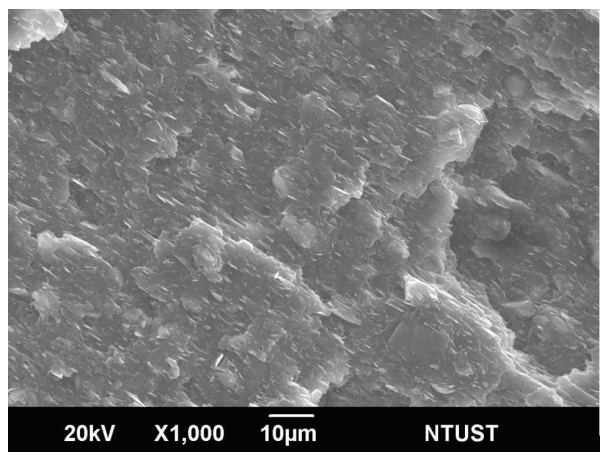

(c) PLA

FIGURE 9: SEM micrographs of impact fractured at room temperature. The white arrows in (a-b) point to the break tracks.

break cross-section with a directive layer (Figures 9(a) and 9(b)), but the PLA/PBAT (50/50) has a higher directive layer than the PLA/PBAT (70/30). The PLA/PBAT (50/50) break cross-section also shows a concave region with long narrow edge. The patterns of appearing in the break cross-section confirm that the irregular and directive layer morphologies for PLA/PBAT (50/50) and PLA/PBAT (70/30) result from the PLA fiber shape (Figures 8 and 9). Although PLA has no obvious fiber shape or directive morphology, it presents the break further of acute angle and has a high degree of crystallization (Figure 9(c)). Therefore, the PLA has a lower impact strength compared to PLA/PBAT (50/50) and $\mathrm{PLA} / \mathrm{PBAT}$ (70/30) blends. The results in this section indicate that the PBAT content in blends and the morphologies of blends improve the impact strength of PLA.

3.3. Effect of Annealing on the Mechanical Properties. Annealing generally has a positive effect on improving mechanical properties. All samples in this study were undergone annealing at $100^{\circ} \mathrm{C}$ for $8 \mathrm{~h}$ and $24 \mathrm{~h}$. Figures $6(\mathrm{~b})-6(\mathrm{c})$ and Table 4 show their tensile strength and impact strength. The initial modulus and the stress at break for PLA/PBAT blends increased after annealing, but their strain at break and impact strength decreased. These results are likely due to crystallization and the morphology. According to the DSC and WAXD results, annealing increased the degree of crystallization for PLA/PBAT blends and PLA. Accordingly, the morphology and degree of crystallization have negative effect on the impact strength of PLA/PBAT blends (Table 4). After annealing, the impact strength of PLA/PBAT blends decreased compared to those of the PLA and PBAT. This is likely because the PLA/PBAT (70/30) and PLA/PBAT (50/50) had fiber-shaped morphologies. Therefore, the development of crystallization for the PLA/PBAT (70/30) and PLA/PBAT (50/50) under the annealing process is along the direction of a bunch of fiber shapes. Accordingly, the directive crystallinity of blends increases their strength and initial modulus but reduces the elongation of the blend. However, the impact strength of PLA/PBAT (70/30) and PLA/PBAT (50/50) after annealing decreases because of the directive crystallinity resulting from the fiber-shape morphology (Table 4 and Figure 8 ). As the directive crystallinity in the blends undergoes impact force, a crack will result in array along the direction of crystallization. Accordingly, the blends present an acute-angle break cross-section with a directive layer morphology (Figures 9(a) and 9(b)). Similarly, the impact strength of PLA/PBAT (30/70) after annealing decreases because of a high degree of PLA crystallinity, island-phase morphology, and amorphous PBAT sea phase. The morphology of rubber toughening is generally caused by rubber particles dispersed in the continuous phase of the plastic. Rubber has a high elongation ability and impact strength, but its modulus is low. Therefore, it is easy to elongate along the stress direction, and the load is primarily borne by the continuous phase of the plastic [16]. The morphology of PLA/PBAT (30/70) is the opposite of rubber toughening; the PBAT continuous phase bears most of the load, and the PLA dispersed phase plays the role of 


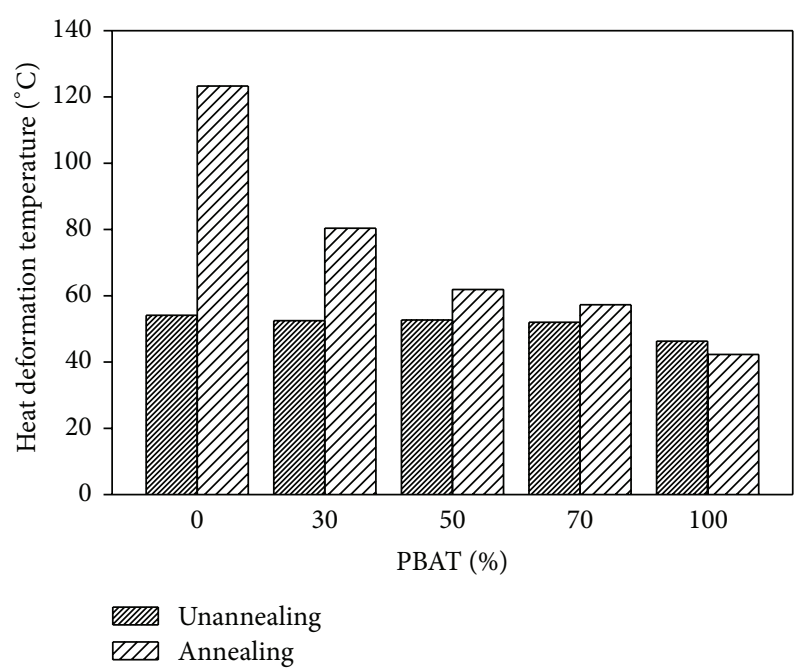

FIGURE 10: Relationship between heat deformation temperature and composition of the PLA/PBAT.

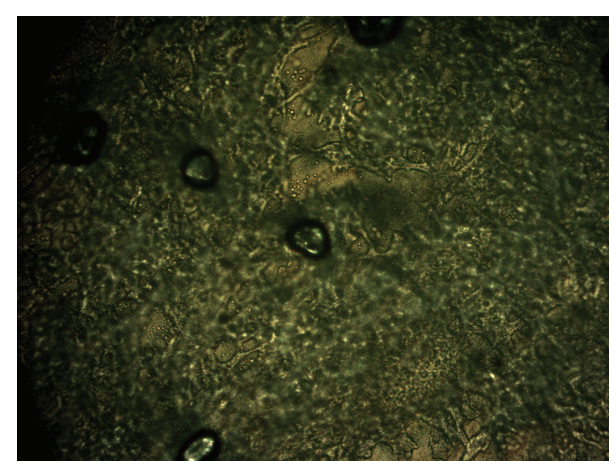

FIgURE 11: POM micrograph of PLA/PBAT (30/70) in the quenching process.

reinforcement. Therefore, the untreated PLA/PBAT (30/70) has a high impact strength and good elongation ability but its high degree of crystallization after annealing causes a low impact strength and low tensile strength. However, the high degree of crystallization after annealing improves its heat deflection temperature (HDT) (Figure 10). Thus, the PLA HDT increases after annealing. The effect of crystallinity on the HDT is revealed on the degree of improvement for the blends and HDT is very lower than the PLA. The PBAT decreases after annealing, and the PLA exhibits a high degree of crystallinity, according to the results of WAXD and DSC. Accordingly, the HDT is significantly affected by the degree of crystallization. However, the morphology of the blends has obvious effect. After annealing for $24 \mathrm{~h}$, the PLA HDT reaches $128.5^{\circ} \mathrm{C}$, which is a significant improvement over the PLA HDT.

\section{Conclusion}

The PLA/PBAT blends in the DSC analysis exhibit two glass transition regions, indicating that the blends are immiscible. Therefore, the PLA/PBAT blends have a two-phase structure. The morphologies of the two-phase structure for PLA/PBAT (30/70), PLA/PBAT (50/50), and PLA/PBAT $(70 / 30)$ blends in the SEM, respectively, exhibit sea-island, directive layer, and irregular-layer morphologies, respectively. The morphology of PLA/PBAT (50/50) showed a major effect on the mechanical properties. The PLA/PBAT (70/30) composition has higher impact strength than PLA/PBAT (50/50) composition. This result is because the PLA/PBAT (50/50) has directive layer morphology. Accordingly, the morphology of PLA/PBA blends has a significant effect on mechanical properties, except for the PBAT content. The mechanical properties of PLA exhibit low-strain and highstress characteristics; therefore, the toughness of PLA is low in practical applications. Conversely, PBAT presents a low stress but has high strain. Accordingly, low-strain and high-stress properties of the PLA are complementary with elastomeric of the PBAT. Both morphology and composition of the blends are determinants of their impact strength. In this study, the PLA/PBAT (30/70) blends are an optimal condition that it presents the highest elongation, better impact strength with sea-island morphology. Annealing increased the degree of crystallization in the blends, raising their initial modulus, stress, and HDT, but reducing their impact strength. The directive layer morphology of the blends produced a directive crystal causing the large decrease in impact strength after annealing.

\section{References}

[1] M. Sheth, R. A. Kumar, V. Davé, R. A. Gross, and S. P. Mccarthy, "Biodegradable polymer blends of poly(lactic acid) and poly (ethylene glycol)," Journal of Applied Polymer Science, vol. 66, no. 8, pp. 1495-1505, 1997.

[2] M.-A. Paul, M. Alexandre, P. Degée, C. Henrist, A. Rulmont, and P. Dubois, "New nanocomposite materials based on plasticized poly(L-lactide) and organo-modified montmorillonites: thermal and morphological study," Polymer, vol. 44, no. 2, pp. 443-450, 2002.

[3] X. Ma, Y. Jiugao, and N. Wang, "Compatibility characterization of poly(lactic acid)/ poly(propylene carbonate) blends," Journal of Polymer Science B, vol. 44, no. 1, pp. 94-101, 2006.

[4] S. Lee and J. W. Lee, "Characterization and processing of Biodegradable polymer blends of poly(lactic acid) with poly (butylene succinate adipate)," Korea Australia Rheology Journal, vol. 17, no. 2, pp. 71-77, 2005.

[5] L. Jiang, M. P. Wolcott, and J. Zhang, "Study of biodegradable polylactide/poly(butylene adipate-co-terephthalate) blends," Biomacromolecules, vol. 7, no. 1, pp. 199-207, 2006.

[6] W. Zhang, L. Chen, and Y. Zhang, "Surprising shape-memory effect of polylactide resulted from toughening by polyamide elastomer," Polymer, vol. 50, no. 5, pp. 1311-1315, 2009.

[7] S. Sinha Ray, K. Yamada, M. Okamoto, A. Ogami, and K. Ueda, "New polylactide/layered silicate nanocomposites. 3. Highperformance biodegradable materials," Chemistry of Materials, vol. 15, no. 7, pp. 1456-1465, 2003.

[8] K. Sadayuki, O. Shinichiro, and K. Jiro, "Polylactic acid resin composition and method for producing the same," Toray Industries, JP 2004250549, 2004. 
[9] F. Signori, M.-B. Coltelli, and S. Bronco, "Thermal degradation of poly(lactic acid) (PLA) and poly(butylene adipate-coterephthalate) (PBAT) and their blends upon melt processing," Polymer Degradation and Stability, vol. 94, no. 1, pp. 74-82, 2009.

[10] H. Xiao, W. Lu, and J.-T. Yeh, "Crystallization behavior of fully biodegradable poly(lactic acid)/poly(butylene adipate-coterephthalate) blends," Journal of Applied Polymer Science, vol. 112, no. 6, pp. 3754-3763, 2009.

[11] J.-T. Yeh, C.-H. Tsou, C.-Y. Huang, K.-N. Chen, C.-S. Wu, and W.-L. Chai, "Compatible and crystallization properties of poly (lactic acid)/poly(butylene adipate-co-terephthalate) blends," Journal of Applied Polymer Science, vol. 116, no. 2, pp. 680-687, 2010.

[12] S. Farsetti, B. Cioni, and A. Lazzeri, "Physico-mechanical properties of biodegradable rubber toughened polymers," Macromolecular Symposia, vol. 301, no. 1, pp. 82-89, 2011.

[13] K. Li, J. Peng, L.-S. Turng, and H.-X. Huang, "Dynamic rheological behavior and morphology of polylactide/poly(butylenes adipate-co-terephthalate) blends with various composition ratios," Advances in Polymer Technology, vol. 30, no. 2, pp. 150157, 2011.

[14] IUPAC, "Definitions of terms relating to phase transitions of the solid state," Pure and Applied Chemistry, vol. 66, no. 3, pp. 577$594,1994$.

[15] O. Olagoke, Polymer-Polymer Miscibility, Academic Press, London, UK, 1979.

[16] M. L. Robeson, Polymer Blends: A Comprehensive Review, Hanser, Munich, Germany, 2007.

[17] T. Ke and X. Sun, "Effects of moisture content and heat treatment on the physical properties of starch and poly(lactic acid) blends," Journal of Applied Polymer Science, vol. 81, no. 12, pp. 3069-3082, 2001.

[18] M. Pluta, "Morphology and properties of polylactide modified by thermal treatment, filling with layered silicates and plasticization," Polymer, vol. 45, no. 24, pp. 8239-8251, 2004. 

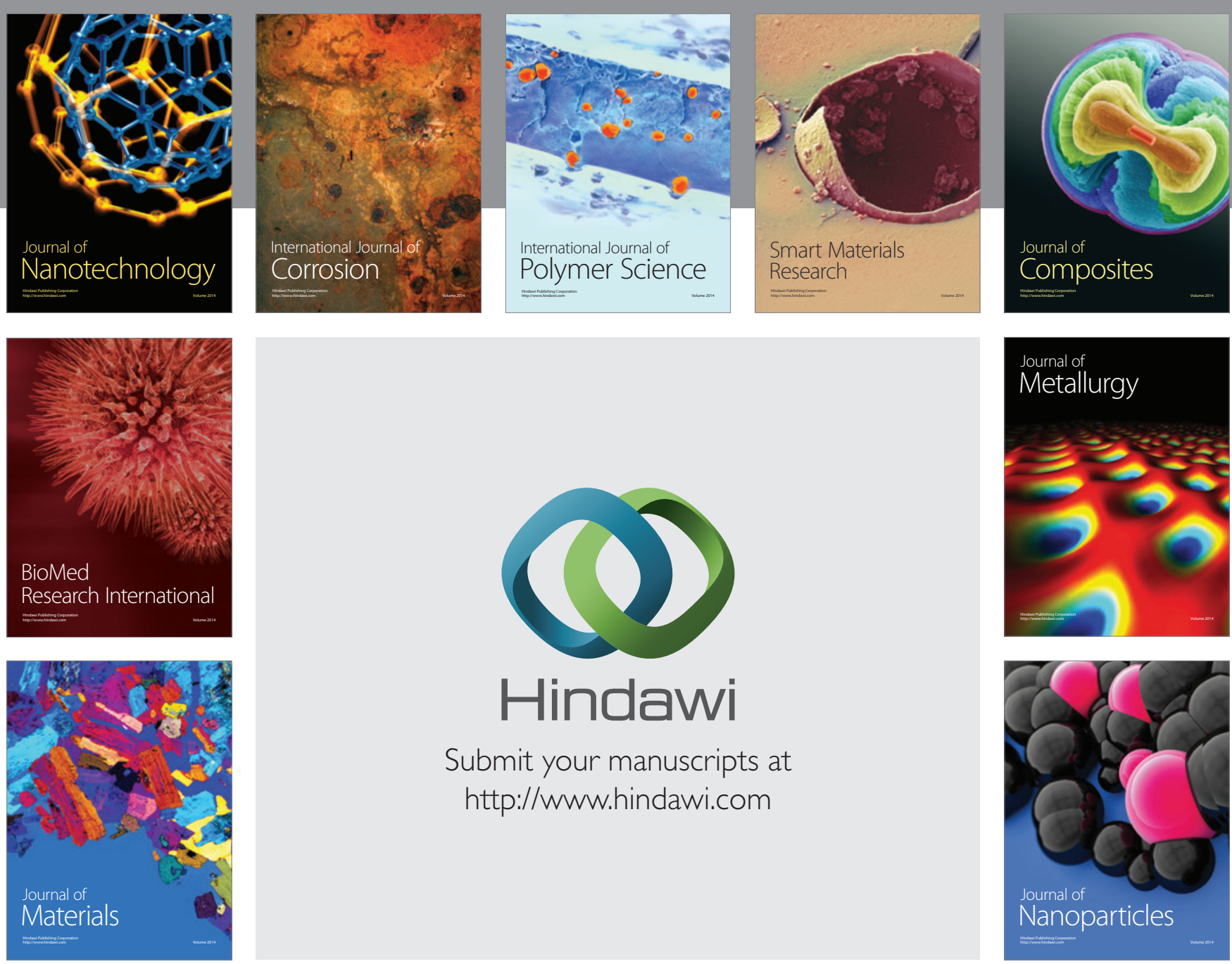

Submit your manuscripts at http://www.hindawi.com
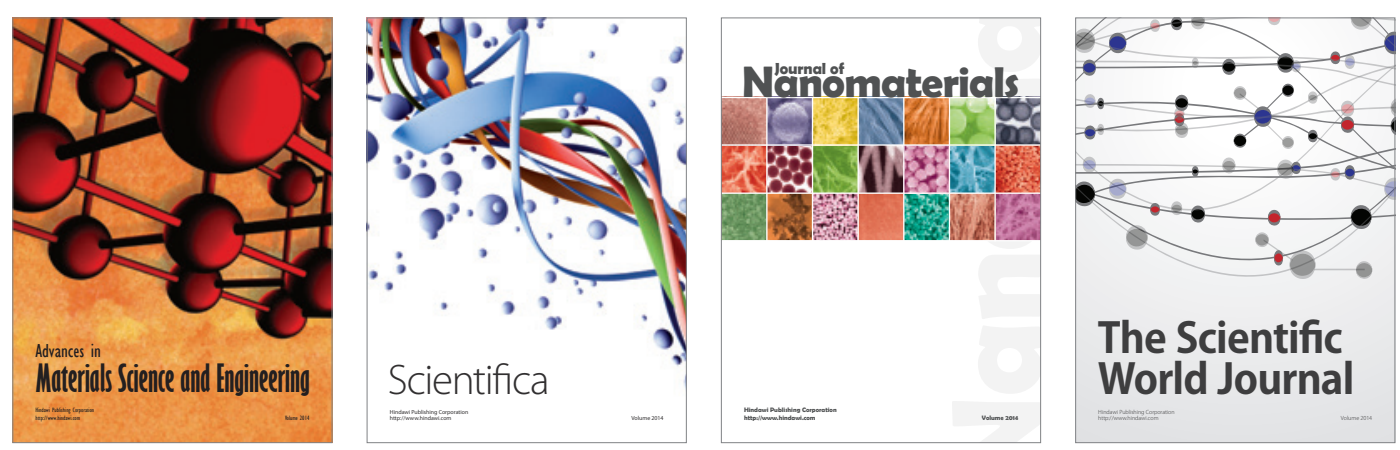

\section{The Scientific World Journal}
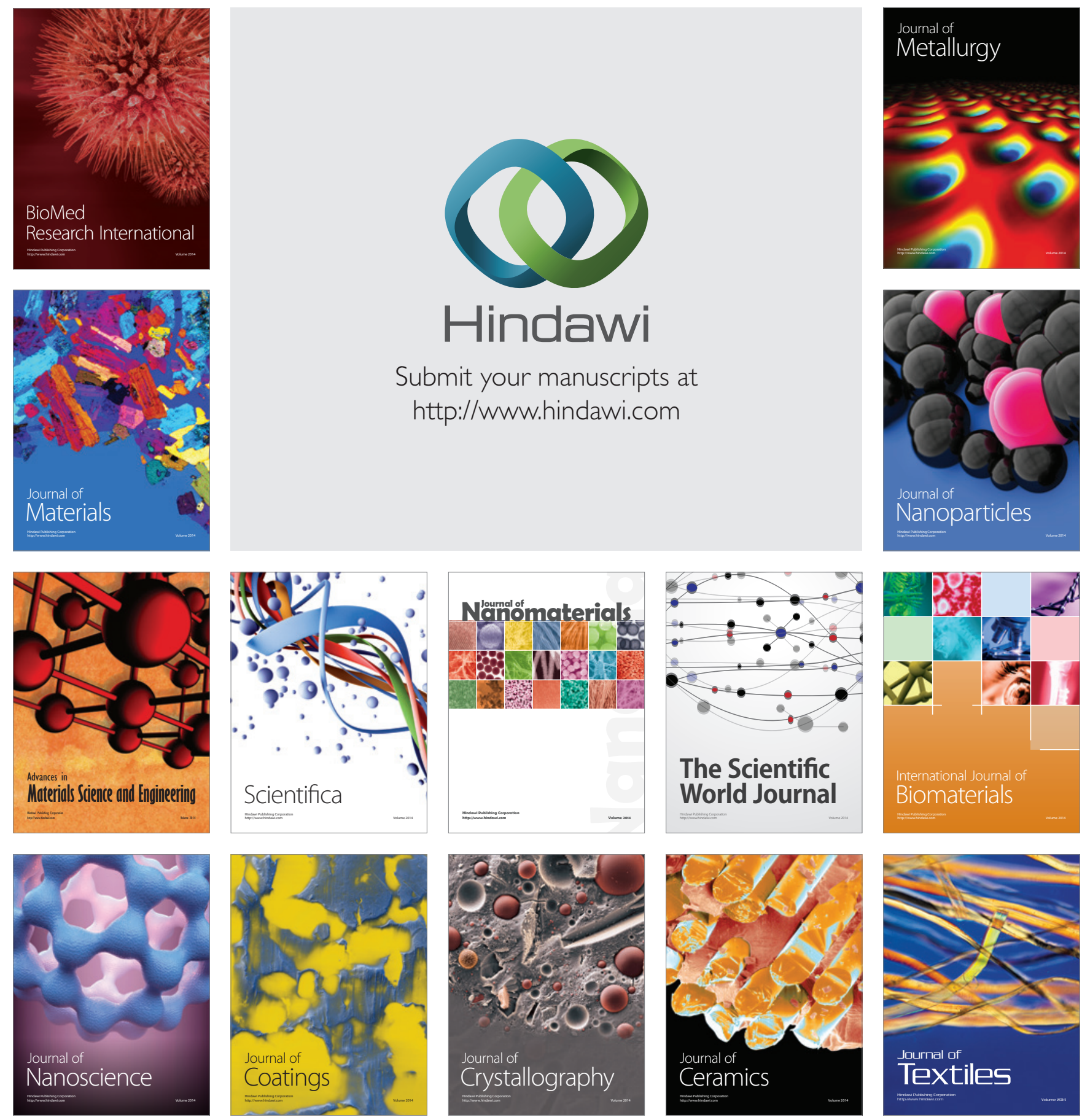